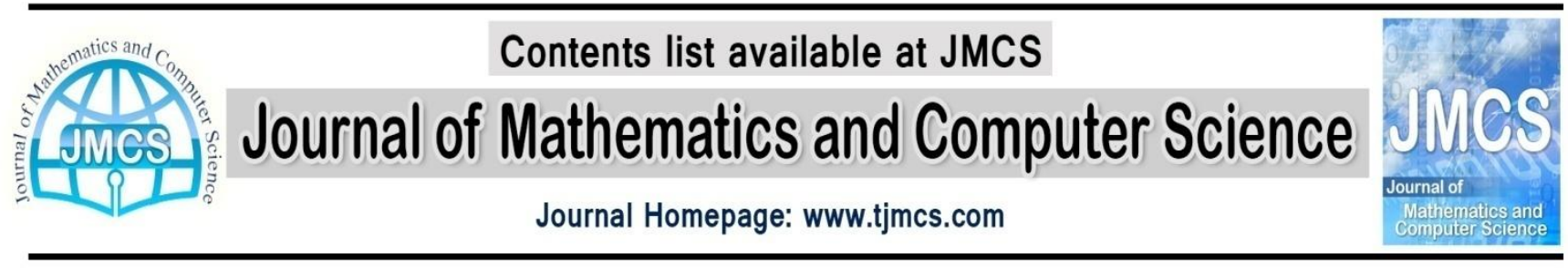

\title{
Presentation the decision making model, in order to the optimality of using solar panels and wind turbines instead of usual power in places with limited use
}

\author{
Hesamoddin Salarian ${ }^{1}$, Hadi Kashefi ${ }^{2}$ \\ ${ }^{1,2}$ Department of Mechanical Engineering, Nour Branch, Islamic Azad University, Nour, Iran \\ h_salaryan@yahoo.com; hadi.kashefi64@gmail.com
}

Article history:

Received January 2014

Accepted March 2014

Available online March 2014

\begin{abstract}
In general, as a source of lightening, heat and cold and in particular, in business and industry, electricity can be considered as the most commonly applied energy in the communities. The researcher, scholars and policymakers are required to see into the future of electricity because it has been significantly demanded as an efficient fuel for economic growth and development with no pollution. Having reviewed various models of electric energy, the current research is intended to present a mathematical model in order to evaluate the utilization of wind, solar and power plants for the places with limited use, the results showed that using such plants from the national network of electricity.
\end{abstract}

Keywords: Solar energy, wind energy, cost model

\section{Introduction}

Today, all people depend on energy production and consumption in order live. Therefore, energy supply and demand has permanently increased in human communities. Currently, $77 \%$ of global energy consumption is supplied by fossil fuel which seriously threatens the environment and makes the earth warmer due to greenhouse and pollutant gasses created by destruction of ozone layers.

Hence, a necessity of doing such current research is to study reduction of the greenhouse and pollutant gasses. The second necessity of doing this research is to study the costs of using this clear energy. Because the distant villages with limited use cost high to be supplied by national electricity network. Also, the current research is intended to study how the costs of such projects will be compared to the costs of electricity transfer in national network. 


\section{Research background}

In 2005, a wind solar system developed by two models was provided to generate electricity. The first model regards different methods of generation as in pout in terms of costs and the most real method with lowest cost for electricity generation is considered as output. The second method is based on linear planning. And the most optimal model is provided by liner planning techniques [1].

The research by Martin J. Pasqualetti and Susan Hag [2] in the University of Arizona, refers to the economic review of using solar panels and considers energy yield. In addition, the need to use solar energy for electricity generation in order to save costs is clearly de menstruated in their research. The article entitled "the price of wind power in china during its expansion" written by Laura D. Anadon and Yueming Qiu, at the university of Stanford, investigated the costs of using wind energy as compared to the costs of other wind generation methods [3]. They showed that using wind energy can reduce $4.1 \%$ the as compared to other manners of energy yield.

Raul Morais et al managed to investigate solar and wind energy as simultaneously used to generate electricity in vast area farms. They clearly observed the positive effects of using such new energy sources as wind and sun on reducing costs of electricity consumption and energy management, their investigations could be used in a model developed for energy management. In a research for electricity generation in American state of Minnesota. The results showed that those sources could be utilized for electricity generation through management of using new energies during all seasons [4].

Additionally, the experiences of the countries which have been active in production of new energies will be used here, Denmark, Spain, Portugal, and Germany are ranked as the countries with highest levels of wind electricity generation with $20 \%, 9 \%$ and $7 \%$, respectively. In 2011, the researchers studied using wind turbines in small places. One of the prominent problems with wind turbines is their failure to producelsland energy. This problem could be solved by simultaneously using the solar panels [5].

Parm Pal Singh and Sukhmeet Singh (2010) studied the costs of using solar energy in India. Here, their results are used for model provision.

Several Iranian researchers studied the costs of using new energies including wind and solar energies. In an article entitled "an estimation of solar radiation for using solar plants in Iran" ,Mr Moini studied solar energy uses in their country. [6]

In an article entitled "an economic review of the photovoltaic systems to supply the electricity of the villages without power", Monshipour compared all costs of a photo voltaic system and the costs of national electricity transmission network. They concluded that when a village is less populated and is distant from the national transmission network, using photo voltaic system of the usual power will be more cost effective [7].

\section{Solar energy}

Sun is one of the two energy sources which doesn't need costly and high technologies, it can be used as a helpful source of energy across the world. The oil crises 70 s contributed to extensive efforts of research and progress mostly focused on solar energy all renewable energies are based on sun. 


\subsection{Photovoltaic systems and dispersed electricity generation}

Today, different types of dispersed electricity generation systems PV are evolved in such a manner that they include local supply (independent small load), regional supply (loads of public and welfare facilities) and cross-regional supply (connection with electricity distribution network). These types of dispersed supply could be developed step by step in parallel with increase in demands. Significant extension of dispersed electricity transmission will automatically connect the local networks and will create regional and cross-regional networks. In these dispersed structures, communication economically becomes a key item for safety system. In addition to control and monitor the power line connection, different parts and the plants the communication structures are necessary for dispersed structures need to be equipped with appropriate communication technologies. Clearly, application of modern communication technologies should influence on designing the supply constituents and system [8].

It is predicted that such dispersed supply structures show the future stable energy production systems and the effective method of production systems and the effective method of electricity distribution for the distant villages. Also, the current trend of dispersed electricity distribution structures in industrialist countries has demonstrated this. Reduced prices due to application of such new electric parts as charge. Regulators for PV small system, AC/AC converters, control systems and observation of extended systems will be expected. This in particular holds for those systems provided in modular or block forms.

\subsection{Applications of photovoltaic systems in Iran}

Given the fact that Iran enjoys a higher potential of solar energy, it seems necessary to investigate this kind of energy and long term investments to use, the sun validates $4 \mathrm{KWH}$ daily per a square meter across the country. In medium, the sun shines for 2800 hours annually. This increases to 3200 hours in a year for the desert regions. It indicates the country is highly potential to use solar energy. So, several plans have been operationalized in order to use solar energy.

Regarding the information available for those firms which are active in terms of photovoltaic, currently the photovoltaic systems, as separated from the electricity network, are used to supply the electricity of such small users as real lighting systems, intercity telephone systems, mobile chargers, electronic units. Consequently, it might be said that Iran in its early path toward applying photovoltaic electricity and the country expects to pass a long road toward this issue [7].

\subsection{The price of main elements of a photovoltaic system}

The main negative characteristic of the PV systems, in terms of higher power generation, is to attract the early investment which demands public and private supports through appropriately allocation subsides in order to make the public welcome the solar electricity. In order to better investigate the costs of a photovoltaic system, the figures and statistics available at http://www.solarbuzz.com, one of the mostly credited research and consolation centers of solar energy, will be considered here. The modules account for 50 to $60 \%$ of the costs of an installed photovoltaic system. Therefore, price is one of the main parts the photovoltaic systems. The inverter accounts for about $10 \%$ of the costs of an installed photovoltaic system. The batteries are usually used in the photovoltaic systems as separated from the network. The batteries account for a higher percentage (about $50 \%$ ) of the costs of the 
installed photovoltaic system. Also, the control charge is used in the photovoltaic systems as separated from the network. The control charge accounts for $10 \%$ of the costs of an installed photovoltaic system as separated from the network. Table 1 shows the prices of a photovoltaic system since July 2012 to march 2013[8].

Table 1- prices of the elements of a photovoltaic system, July 2012-March 2013

\begin{tabular}{|c|c|c|c|c|c|}
\hline \multicolumn{2}{|c|}{} & Modulator & Inverter & Battery & Charge Controller \\
\hline \multirow{2}{*}{ Jul2012 } & USD & 3.02 & 0.715 & 0.213 & 5.93 \\
\cline { 2 - 6 } & EUR & 2.54 & 0.500 & 0.149 & 4.15 \\
\hline \multirow{2}{*}{ Sug2012 } & USD & 2.84 & 0.714 & 0.213 & 5.93 \\
\cline { 2 - 6 } & EUR & 2.51 & 0.500 & 0.149 & 4.15 \\
\hline \multirow{2}{*}{ Oct2012 } & USD & 2.65 & 0.714 & 0.213 & 5.93 \\
\cline { 2 - 6 } & EUR & 2.43 & 0.500 & 0.149 & 4.15 \\
\cline { 2 - 6 } & USD & 2.60 & 0.714 & 0.213 & 5.93 \\
\hline \multirow{2}{*}{ Eov2012 } & USD & 2.37 & 0.528 & 0.158 & 4.39 \\
\cline { 2 - 6 } & EUR & 2.49 & 0.714 & 0.213 & 5.93 \\
\hline \multirow{2}{*}{ Dec2012 } & USD & 2.43 & 0.528 & 0.158 & 4.39 \\
\cline { 2 - 6 } & EUR & 2.33 & 0.713 & 0.213 & 5.93 \\
\hline \multirow{2}{*}{ Jan2013 } & USD & 2.42 & 0.712 & 0.160 & 4.45 \\
\cline { 2 - 6 } & EUR & 2.31 & 0.548 & 0.164 & 5.93 \\
\hline \multirow{2}{*}{ Feb2013 } & USD & 2.30 & 0.711 & 0.213 & 5.93 \\
\cline { 2 - 6 } & EUR & 2.28 & 0.540 & 0.162 & 4.51 \\
\hline \multirow{2}{*}{ Mar2013 } & USD & 2.29 & 0.711 & 0.213 & 5.93 \\
\cline { 2 - 6 } & EUR & 2.17 & 0.526 & 0.158 & 4.39 \\
\hline
\end{tabular}

\section{Wind energy}

Wind energy has been considered important for the human being. Historically, wind has been utilized as a vital source of movement over the water. The marine businessmen and discoverers were moving by using this immortal source. The wind energy has been used to make the mills and water wheels move to pump water. Wind has been historically considered as an important source. The wind doesn't blow in equal amounts across all of the earth. It blows more strongly over the sea surface and plain regions than the urban areas and jungles. Such barriers as trees, buildings and different facilities can reduce the speed of wind. However, its effect reduces in heights. In addition, the wind highly depends on the large scale water systems. For instance, the gulf stream water flow makes powerful winds blow across southwestern Ireland. The windy disturbances pass across the Atlantic Ocean and generally move toward Ireland. Today, the wind not only is important because of milling and pumping water, but it is also important as a source of electric energy in windy regions.

\subsection{Wind energy in Iran}

Given the fact that designing and building wind mills was common in 200 B.C and also given the fact that currently good condition is provided to widely operationalize the windy turbines, the estimations and investigations done on wind energy potentials in Iran indicated that only in 26 regions of the 
country (more than 45 sites), the nominal capacity of the sites regarding the total efficiency of $33 \%$ is about $6500 \mathrm{mw}$. In this situation, all national power plants have a nominal capacity of $3400 \mathrm{MW}$.

In 2004, only $25 \mathrm{MW}$ of the $3300 \mathrm{MW}$ was generated by energy wind in Iran. In 2006, $45 \mathrm{MW}$ was generated by wind energy in Iran. It indicated a $40 \%$ growth as compared to 2005. In 2008, Manjil's wind plant in Gilan province and Binalood's wind plant in Razavi Khorasan province were generating 82 MW of electricity. In 2009, Iran has gotten a wind electricity capacity of $130 \mathrm{MWH}$.

\subsection{Costs of using wind energy}

The costs of using wind turbines reduced $80 \%$ during late 20 years. Since the beginning 1980's when the first wind turbines of larger sizes were installed, the costs of energy production by wind was 30 cents per a kwh. This is while the cost of energy production by large wind plants reached to about 3 cents per kwh. This amount seems to compete other conventional energy source.

The costs of wind plants highly depend on the establishment of wind plants which influence on wind's speed and the costs of distribution channel in a region. Currently, the wind plants located in windy regions can generate cheaper electricity as compared to the plants with fossil fuels. This is while the costs of the fossil plants seem to increase. With respect to this trend, the costs of producing wind energy will reduce more than the energy produced from the conventional fossil energy. Figure 1shows the prices of the elements of a system of electric production by wind.

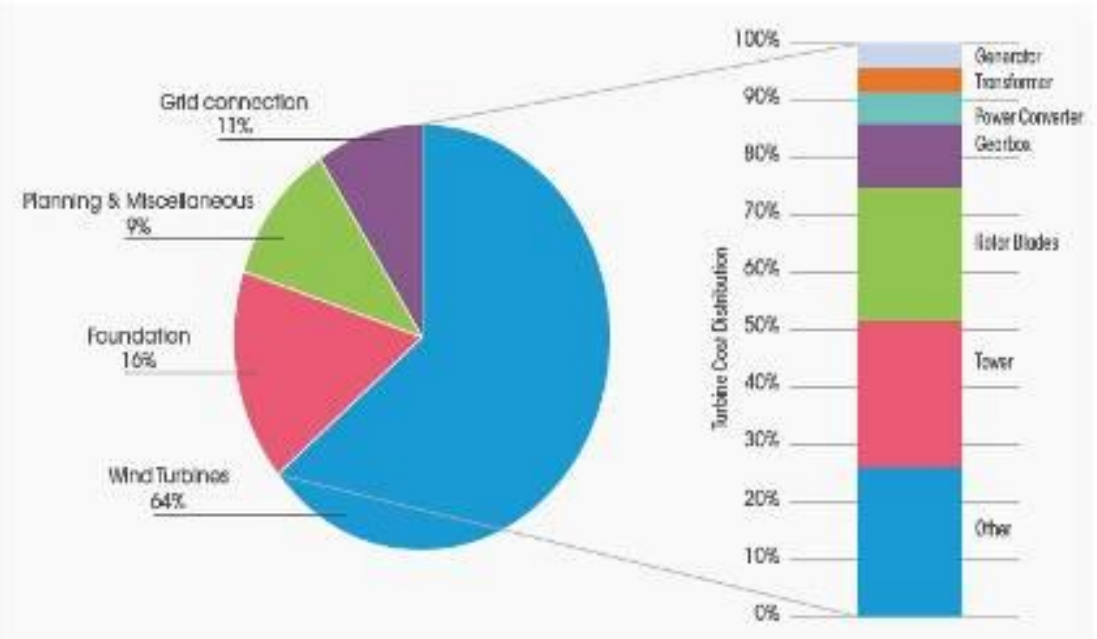

Figure 1- prices of the elements of electric energy production by wind.

\section{Parameters, variables, limitations and provision of the model}

Having studied the costs which could be provided in the model, the model will be provided and its solution for different climates of Iran will be presented. First, the costs of using each of the sources will be determined. Table 2 shows the details of the costs of using solar and wind plants and using the usual power.

W: electricity generated by wind energy

S: electricity generated by solar energy 
U: electricity generated by usual power.

Cw: total cost of electricity generated by wind energy

Cs: total cost of electricity generated by solar energy

$\mathrm{Cu}$ : total cost of using usual power per unit

a : Low consumption

b :high consumption

Table 2- Details of the costs of using solar and wind plants and using usual power

\begin{tabular}{|c|c|c|c|c|c|c|}
\hline & $\begin{array}{c}\text { Preparation } \\
\text { cost (per } \\
\text { unit) }\end{array}$ & $\begin{array}{c}\text { Production or } \\
\text { purchase cost } \\
\text { (per unit) }\end{array}$ & $\begin{array}{c}\text { Manpower } \\
\text { costs(per } \\
\text { unit) }\end{array}$ & $\begin{array}{c}\text { Maintenance } \\
\text { costs(per unit) }\end{array}$ & $\begin{array}{c}\text { greenhouse gas } \\
\text { emissions } \\
\text { Costs(per unit) }\end{array}$ & $\begin{array}{c}\text { network } \\
\text { connectivity } \\
\text { Costs }\end{array}$ \\
\hline W & Crw & Cgw & Chw & Cfw & - & - \\
\hline S & Crs & Cgs & Chs & Cfs & - & - \\
\hline U & - & Cgu & - & - & Cpu & Ccu \\
\hline
\end{tabular}

\subsection{Limitations of wind speed (Sw is speed of wind blowing)}

The results from the provided model showed that it is not cost effective to use wind turbines when the wind blows with a speed less than $3 \mathrm{~m} / \mathrm{s}$. Also, with respect to the previous results, in places where the wind blows 3 to $7 \mathrm{~m} / \mathrm{s}, \beta=2$ will be considered for costs of using wind energy.

$\mathrm{Sw}<4(\mathrm{~m} / \mathrm{s})$
$4 \leq \mathrm{Sw}<7(\mathrm{~m} / \mathrm{s})$ $\begin{aligned} & \text { Wind energy is not allowed to use } \\ & \text { Usw }(\mathrm{m} / \mathrm{s})\end{aligned} \quad \begin{aligned} & \text { Use } \mathrm{B}=2 \\ & \text { Wind energy is allowed to use }\end{aligned}$

\subsection{Limitations of the number of sun hours (As)}

Another important parameter for the above-mentioned model is the effects of sun hours on electric energy production. Here, the number of sun hours was calculated for 160 synoptic stations annually which could be used as a reference. For the investigations renewable energy organization of Iran, 4 limits were set for determining the costs of solar plants as compared to the number of sun hours in a year. Here, these 4 limits will also be used. First limit involves those places with radiation less than 1000 hour in a year and it is not technically possible to use solar energy. In places where radiation is between 1000 to 2000 hours in a year, the desirable result will be obtained by $\mu=2$ and in places where radiation is between 2000 to 2500 hours in a year, the desirable result will be obtained by $\mu=15$. Additionally, in places where sun radiation is more than 2500 hours in a year, using solar energy is technically confirmed. 


$\begin{array}{lll}\text { As }<1000 \quad \text { (hours/year) } & \rightarrow & \text { Solar energy is not allowed to use } \\ 1000 \leq \text { As }<2000 \text { (hours/year) } & \rightarrow & \text { Use } \mu=2 \\ 2000 \leq \text { As }<2500 \text { (hours/year) } & \rightarrow & \text { Use } \mu=1.5 \\ 2500 \leq \text { As } \quad \text { (hours/year) } & \rightarrow & \text { Solar energy is allowed to use }\end{array}$

Definition of $\mathbf{M}$ : Given the fact that it is impossible to use solar and wind energies with wind blowing at lee than $4 \mathrm{~m} / \mathrm{s}$ and sun radiation less than 1000 hours in a year, with defining this parameter and a total value of 100000000 in the model, it will be possible to use such sources in the model.

Fixed cost: In terms of electricity consumption, the fixed cost of building solar and wind plants and cost of power transmission are considered as Fw, Fs and Fu respectively.(1: when used, 0: when not used).

Yi: the variables 0 and 1 for wind speed

di: the variables 0 and 1 for the number of hours sun radiation in a year

हi: the variables 0 and 1 for fixed cost

\section{Model:}

$\mathrm{MINZ}=\mathrm{C}_{\mathrm{W}} \times \mathrm{W}\left(\mathrm{MY}_{1}+2 \mathrm{Y}_{2}+\mathrm{Y}_{3}\right)+\mathrm{C}_{\mathrm{s}} \times \mathrm{S}\left(\mathrm{M} \delta_{1}+2 \delta_{2}+1.5 \delta_{3}+\delta_{4}\right)+\mathrm{C}_{\mathrm{U}} \mathrm{XU}+\varepsilon_{1} \mathrm{~F}_{\mathrm{W}}+\varepsilon_{2} \mathrm{~F}_{\mathrm{s}}+\varepsilon_{3} \mathrm{Fu}_{\mathrm{U}}$

St:

$$
\begin{aligned}
& a \leq W+S+U \leq b \\
& S_{W}<4 Y_{1} \\
& 4 Y_{2} \leq S_{W}<7 Y_{2} \\
& 7 Y_{3} \leq S_{W} \\
& A_{S} \leq 1000 \delta_{1} \\
& 1000 \delta_{2} \leq A_{S}<2000 \delta_{Y} \\
& 2000 \delta_{3} \leq A_{S}<2500 \delta_{r} \\
& 2500 \delta_{4} \leq A_{S} \\
& Y_{1}+Y_{2}+Y_{3}=1 \\
& \delta_{1}+\delta_{2}+\delta_{3}+\delta_{4}=1 \\
& \varepsilon_{i}=0 \text { or } 1 \\
& Y_{i}=0 \text { or } 1 \\
& \delta_{i}=0 \text { or } 1 \\
& W, S, U \geq 0 \\
& S_{W}, A_{S} \geq 0
\end{aligned}
$$




\section{Case studies}

The current article is intended to study the prices of $1 \mathrm{kwh}$ electricity generated by photovoltaic elements and also the prices of electricity generated by wind turbines and the price of electricity purchased from the national distribution network. Having consulted by the experts at Power Company, The normalized prices of $1 \mathrm{KWH}$ generated by these sources were determined. Therefore, given the fact that the speed of wind and the hourly sun radiation in a year were determined, several places with different characteristics were evaluated, the results of which are shown in table 3.

Table 3- Results from implementing the model in five places

\begin{tabular}{|c|c|c|c|c|c|c|}
\hline NUM & As & Sw & The distance from the network(km) & S\% & W\% & U\% \\
\hline $\mathbf{1}$ & 1842 & 4.2 & 0 & 0 & 0 & 100 \\
\hline $\mathbf{2}$ & 2829 & 4.8 & 20 & 77 & 23 & 0 \\
\hline $\mathbf{3}$ & 1620 & 3.1 & 3 & 0 & 0 & 100 \\
\hline $\mathbf{4}$ & 2740 & 10.9 & 0 & 20 & 65 & 15 \\
\hline $\mathbf{5}$ & 3380 & 9.1 & 0 & 49 & 51 & 0 \\
\hline
\end{tabular}

\section{Conclusion}

Iran is a vast country with different climates. With respect to different climate parameters, using wind and solar plants in different regions of the country by the model of this article could be studied. This article studies the individual factors influencing on electricity generation by wind including speed of wind, various cost of building plants such as preparation cost, turbines and so forth and also electricity generation by solar energy such as hourly sun radiation in a year, cost of solar panels, inverters and with comparing the costs and consumption levels through the provided model, correct decision making on the amount of using these sources has been made. Also, it will be cost-effective to use solar and wind energies in places distant from the national network as compared to the usual power.

\section{Acknowledgement}

This article is part of the research project with financial assistance and multilateral cooperation of Islamic Azad University, Nour branch.

\section{References}

[1] A.L.B. Heagle, G.F. Naterer, K.Pope, Faculty of Engineering and Applied Science, University of Ontario Institute of Technology, 2000 Simcoe Street North, 2000 Simcoe Street North, Oshawa, Ontario, Canada L1H 7K4, "Small wind turbine energy policies for residential and small business usage in Ontario, Canada" Energy Policy 39 (2011)

[2] Martin J. Pasqualetti , Susan Haag, School of Geographical Sciences and Urban Planning, Coor Hall, 5th Floor, 975 South Myrtle Avenue, Arizona State University, Tempe, AZ 85287-5301, United States," A solar economy in the American Southwest" Energy Policy 39 (2011) 887-893 
[3]Yue ming Qiu , Laura D. Anadon Stanford University, Atmosphere/Energy Program, The Jerry Yang and Akiko Yamazaki, Environment \& Energy Building, 473 Via Ortega, Stanford, CA 94305, USA," The price of wind power in China during its expansion" Energy Economics xxx (2011)

[4] Raul Moraisa,b, Samuel G. Matosb, Miguel A. Fernandesb, Ant'onio L.G. Valentea,b, Salviano F.S.P. Soaresa,b, P.J.S.G. Ferreirac, M.J.C.S. Reisa,b, "Sun, wind and water flow as energy supply for small stationary data acquisition platforms ",computers and electronics in agriculture 64 ( 2008 ) $120-132$

[5] A.L.B. Heagle,G.F .Naterer, K. Pope, Faculty of Engineering and Applied Science, University of Ontario Institute of Technology, 2000 Simcoe Street North, 2000 Simcoe Street North, Oshawa, Ontario, Canada L1H 7K4, "Small wind turbine energy policies for residential and small business usage in Ontario, Canada" Energy Policy 39 (2011)

[6] F. Moini, Iranian Journal of Energy, "an estimation of solar radiation for using solar plants in Iran", Volume 13,No.2,2011

[7] Monshipour, Samira, "an economic review of the photovoltaic systems to supply the electricity of the villages without power", Sixth National Conference on Energy, Iran, 2008

[8] http://www.solarbuzz.com 